\title{
TAMAN BUDAYA DI MANGGA BESAR, JAKARTA BARAT
}

\author{
Syarifa Andari ${ }^{11}$, Rudy Trisno ${ }^{21}$ \\ 1)Program Studi S1 Arsitektur, Fakultas Teknik, Universitas Tarumanagara, andarisyarifa@gmail.com \\ 2)Program Studi S1 Arsitektur, Fakultas Teknik, Universitas Tarumanagara, rudyt@ft.untar.ac.id
}

\begin{abstract}
Abstrak
Indonesia memiliki berbagai macam suku dan budaya. Namun, belakangan ini sering terdengar masalah mengenai intoleransi di Indonesia. Keberagaman etnis dapat menimbulkan ketidak cocokan dalam bermasyarakat. Masing-masing etnis memiliki kebiasaan dan gaya hidup mereka sendiri. Oleh karena itu, proyek ini dibuat dengan maksud untuk meminimalisir masalah tersebut, dengan memberi edukasi kepada masyarakat dari semua kalangan. Edukasi tersebut berbentuk taman budaya di Jakarta, yang memiliki tema bangunan budaya betawi dan budaya tionghoa yang digabungkan, dikarenakan kedua budaya tersebut saling berselingan. Taman budaya disini juga sekaligus dapat dijadikan sebagai third place bagi masyarakat sekitar. Third Place disini berfungsi sebagai perantara antara first place (rumah, hotel, apartemen, tempat tinggal) dan second place (kantor, pertokoan, tempat kerja). Third place disini memiliki fungsi fleksibel, dapat digunakan untuk bersantai hingga membahas pekerjaan bersama rekan kerja. Taman budaya berkonteks arsitektur tradisional, dengan bentuk yang sesuai dan membaur dengan bangunan sekitarnya. Metode perancangan; Pemahaman Kawasan Jakarta Barat; Pemahaman Mengenai Tapak Perancangan; Penetapan Program Bangunan; Penggunaan Metode Energi Positif; Penggunaan Metode Simbiosis; Penggunaan Metode Form follows function; Penggunaan Metode Luo Shu; Hasil Akhir Perancangan. Kesimpulan dari hasil perancangan adalah Taman Budaya di Mangga Besar memiliki tujuan untuk memberikan edukasi kepada masyarakat mengenai budaya Betawi dan Tionghoa. Proyek ini menerapkan beberapa konsep, seperti simbiosis dalam arsitektur, form follows function dan luo shu.
\end{abstract}

\section{Kata kunci: Budaya; Edukasi; Masyarakat; Third Place; Taman}

\begin{abstract}
Indonesia has many kinds of ethnicities and cultures. Unfortunately, nowadays news about intolerance is often heard in Indonesia. diversity of ethnicities could cause incompatibilities. Each ethnic have their habits and lifestyle. In consequence, this project is made to provide education to all kinds of communities. The form of education is a cultural park, that adopts themes of the Betawi and the Chinese culture because both cultures have many resemblances. This cultural park at the same time can be used as a third place for the local citizens. The third place serves as an intermediary between first places (such as houses, apartments, hotels, home) and second places (such as offices, stores, working space). The third place is flexible, it could be used as a place to relax or even having work meetings with co-workers. This Cultural Park has a traditional concept, with the form that blends in with its site region. As for the methods; Site project analysis; Determining building program; Positive energy method application; Symbiosis method application; Form follows function method application; Luo shu method application; Final project result. In conclusion, Mangga Besar Cultural Park has a goal to educate local citizens about the Betawi and Chinese culture. Mangga Besar Cultural park also applies the symbiosis and form follows function concept and luo shu. In conclusion, Mangga Besar Cultural Park has a goal to provide education to citizens about the Betawi and Chinese culture. This project applies some concepts, such as symbiosis in architecture, form follows function, and luo shu.
\end{abstract}

Keywords: Culture; Ethnicities; Local Citizen; Park; Third Place 


\section{PENDAHULUAN}

\section{Latar Belakang}

Jakarta merupakan sebuah kota yang memiliki berbagai macam suku. Betawi merupakan suku leluhur kota Jakarta. Suku betawi memiliki berbagai macam pengaruh dari budaya lain, salah satunya tionghoa. Oleh karena itu terdapat banyak sekali kemiripan yang dimiliki oleh dua kebudayaan tersebut. Namun sayangnya terkadang perbedaan dapat memicu intoleransi sosial. Isu toleransi ini terpicu oleh berbagai macam faktor, yaitu kurangnya pendidikan, pergaulan yang tidak baik, dan faktor-faktor lainnya. Gatot Eddy Pramono menjelaskan bahwa kondisi Indonesia didominasi oleh masyarakat kelas bawah (low class). Masyarakat kelas bawah ini bisa digolongkan sebagai masyarakat yang kurang beruntung dalam mendapat pendidikan, ekonomi, dan lain sebagainya. (Nugraheny, n.d.) Setiap kepercayaan maupun budaya selalu mengajarkan tentang menghargai sesama dan hidup dalam damai. Padahal, jika kita saling mengenal budaya satu sama lain, kita dapat menemukan banyak persamaan. Pemahaman toleransi sebaiknya ditanam sejak dini, serta diajarkan untuk bergaul dengan teman-teman yang baik, tanpa memandang suku, etnis, maupun agama.

\section{Rumusan Masalah}

Bagaimana cara meminimalisir permasalahan mengenai intoleransi dengan arsitektur? Dan Bagaimana cara menggabungkan kedua budaya dalam satu bentuk arsitektur?

\section{Tujuan}

Merancang sebuah third place untuk saling berkumpul dan mengenal masing-masing budaya dan memberi edukasi mengenai budaya betawi dan budaya tionghoa.

\section{Manfaat}

Adapun manfaat dari proyek ini yaitu menyediakan sebuah taman budaya yang dapat digunakan sebagai tempat untuk saling bersosialisasi dan mempelajari mengenai masing-masing budaya. Serta menyediakan bangunan yang memenuhi beberapa aspek sustainable development goals.

\section{KAJIAN LITERATUR}

\section{Third Place}

Menurut Oldenburgh (1997), third place merupakan perantara dari first place, yang berarti tempat tinggal dan second place, yang berarti tempat kerja. Third place disini memberikan fasilitas untuk bersantai, serta memfasilitasi interaksi yang lebih kreatif dan tidak kaku. Menurut (Oldenburgh, 1997) third place dapat diartikan sebagai berikut:

a. Neutral Ground: Tidak terikat secara finasial, politik dan dapat diakses dengan bebas.

b. Leveler (a leveling place): Tidak memandang status sosial.

c. Conversation is the main activity: Tujuan utama dari third place yaitu untuk saling berkomunikasi dan mengenal.

d. Accessibility and accommodation: Mudah terjangkau dan dapat mengakomodasi kebutuhan sekitarnya.

e. The regulars: Mampu menyesuaikan karakteristik kawasan, serta memberi kenyamanan bagi para pengunjung.

f. A low profile: Tidak membeda-bedakan pengunjung.

g. The mood is playful: Third place digunakan untuk hiburan dan berelaksasi, tanpa adanya tekanan.

h. A home away from home: Dapat memberikan suasana yang nyaman.

Dapat disimpulkan bahwa third place merupakan perantara antara first place dan second place, dimana first place merupakan sebuah tempat yang bersifat tempat tinggal (rumah, apartemen, hotel) dan second place merupakan tempat kerja (kantor, sekolah, toko). Third place ini dapat dijadikan sebagai tempat untuk bersantai dan beristirahat sejenak, sebelum atau sesudah dari tempat kerja. 


\section{Permasalahan}

\section{Intoleransi}

Menurut kamus besar Bahasa Indonesia, toleransi merupakan penyimpangan yang masih dapat diterima dalam pengukuran kerja. Menoleransi merupakan mendiamkan atau membiarkan, sedangkan intoleransi merupakan ketiada tenggang rasa. Sosial memiliki arti berkenaan dengan masyarakat dan suka memperhatikan kepentingan umum, serta sifat kemasyarkatan. (KBBI, n.d.) Menurut Hunsberger, intoleran merupakan sebuah tindakan negatif yang dilatari oleh simplifikasi palsu, atau 'prasangka yang berlebihan' (Farid, 2018). Prasangka tersebut memiliki 3 komponen, antara lain:

a. Komponen kognitif mencakup stereotip terhadap 'kelompok luar yang direndahkan.

b. Komponen afektif yang berwujud sikap muak atau tidak suka yang mendalam terhadap kelompok luar.

c. Komponen tindakan negatif terhadap anggota kelompok luar, baik secara interpersonal maupun dalam hal kebijakan politik sosial.

Menurut para antropolog, dari sisi pendidikan, pemerintah sedang menyiapkan unit kerja pemantapan ideologi Pancasila, guna menguatkan kebhinekaan. Dari sisi ekonomi, pemerintah sedang merancang konsep ekonomi baru (new economic policy). Konsep baru ini dimaksudkan untuk meratakan, serta mengurangi kesenjangan ekonomi. Dari sisi hukum, pemerintah akan melakukan proses hukum yang tegas terhadap mereka yang terbukti melakukan tindakan intoleransi (Romadoni, 2017).

\section{Teori Perancangan}

\section{Simbiosis}

Konsep simbiosis dalam arsitektur dirintis oleh Kisho Kurokawa, yang merupakan gabungan antara kedua konsep yang kontradiktif. Namun perbedaan tersebut masih dapat terlihat jelas walaupun digabungkan (Trisno \& Lianto, 2019). Konsep dari budaya betawi dan budaya tionghoa dapat disatukan, baik dari segi interior maupun eksterior.

\section{Bentuk Mengikuti Fungsi}

Konsep bentuk mengikuti fungsi dipelopori oleh Louis Sullivan. Bentuk serta struktur bangunan harus mengikuti fungsi untuk menciptakan sebuah karya arsitektur (Trisno \& Lianto, 2019). Bentuk dari bangunan akan mengikuti ruangan dengan fungsi yang telah diletakkan sesuai mengikuti konsep luo shu.

\section{Energi Positif}

Energi positif pada suatu ruang dapat memberikan dampak yang positif terhadap penggunanya. Energi dapat membuat seseorang ingin menjadi bagian dari sesuatu, oleh karena itu energi positif dibutuhkan (Ahrendts, 2013). Energi positif pada suatu ruang memang dapat membuat pengguna di ruangan tersebut berpikir dan bertindak positif, serta mengurangi pikiran dan tingkah laku negatif dari para pengguna ruang. Seorang arsitek asal Cina bernama Zhang Xi mengutarakan pendapatnya tentang arsitektur, yaitu dengan memaksimalkan energi baik dan mengalihkan energi yang buruk (Benyon, 2019).

Luo Shu

Luo Shu merupakan sebuah naskah dari sungai Lo. Luo Shu digambarkan sebagai 9 kotak yang disusun $3 \times 3$, yang masing-masing kotak memiliki angka dari 1 hingga 9. Masing masing angka diletakkan pada zona tertentu, mengikuti arah mata angin (Sudikno, Salura, \& Kustedja, 2012). Masing masing angka melambangkan sebuah fase, yaitu fase api, fase air, fase kayu, fase logam, dan fase tanah. Fase air melambangkan area yang menenangkan, Fase api melambangkan area yang dapat memuncakkan semangat. Fase logam melambangkan area yang padat. Fase kayu melambangkan pertumbuhan, serta perluasan energi ke segala arah. Fase tanah bergerak secara 
siklis dan mendatar dalam axis (Swetz, 2008). Kotak angka 5 juga biasa disebut sebagai pusat dari aktivitas (Sudikno, Salura, \& Kustedja, 2012)

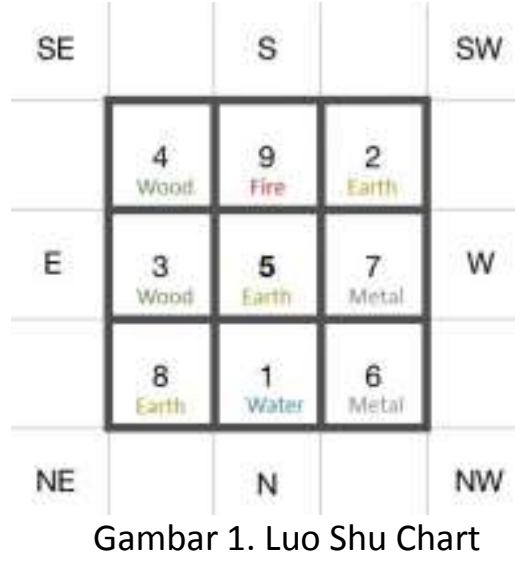

Sumber: Medium.com (2017)

\section{Sustainable Development Goals}

Sustainable Development Goals merupakan rencana aksi global, yang diharapkan dapat mengurangi kemiskinan, mengurangi kesenjangan dan melindungi lingkungan. Berikut aspek yang akan diterapkan pada proyek: 10. Mengurangi ketimpangan / Reduced inequalities Pengunjung semua dianggap sama, dan tidak dibeda-bedakan oleh ras, suku, agama, usia, dan faktor perbedaan lainnya; 11. Pembangunan berkelanjutan / Sustainable cities and communities Third place yang akan dirancang diusahakan dapat digunakan berpuluh-puluh tahun kedepan.;16. Perdamaian dan keadilan / Peace and justice strong institutionsThird place mewujudkan perdamaian para pengunjung. (Sustainable Development Goals, n.d.)

\section{METODE}

Adapun metode dan teknik yang digunakan dalam perancangan, antara lain:

a. Pemahaman Kawasan Jakarta Barat

b. Pemahaman Mengenai Tapak Perancangan

c. Penetapan Program Bangunan

d. Penggunaan Metode Energi Positif

e. Penggunaan Metode Simbiosis

f. Penggunaan Metode Form follows function

g. Penggunaan Metode Luo Shu

h. Hasil Akhir Perancangan

\section{DISKUSI DAN HASIL}

Penentuan Lokasi Perancangan

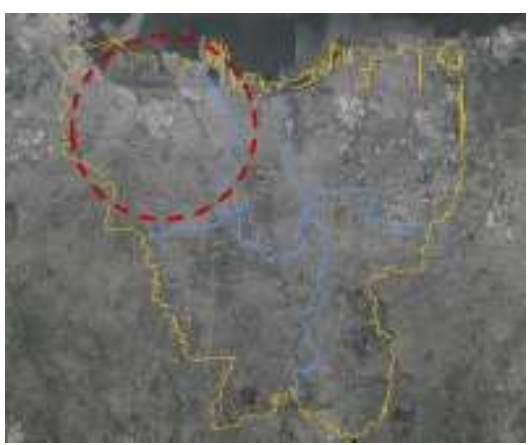

Gambar 2. Pembagian Administrasi Kota Jakarta, Jakarta Barat Dilingkari Merah Sumber: Google Earth (2019) 
Kawasan yang dipilih untuk proyek ini adalah kawasan Jakarta Barat. Jakarta Barat dikenal memiliki kawasan pecinan tertua di Jakarta, yaitu Glodok. Kawasan yang dipilih merupakan kawasan mangga besar, taman sari, jakarta barat. Kawasan tersebut berada di dekat area pecinan, sehingga lebih ragam masyarakat yang terdapat di kawasan tersebut. Menurut data yang diperoleh Badan Penelitian Statistik Jakarta (2019), Jakarta Barat merupakan bagian terpadat dari kota lainnya. Jakarta Barat dipenuhi oleh kawasan first place dan second place. Oleh karena itu, di lokasi yang padat ini, first place dapat memberi manfaat bagi warga sekitar, dengan menambahkan area third place.

\section{Pemahaman Mengenai Tapak Perancangan}

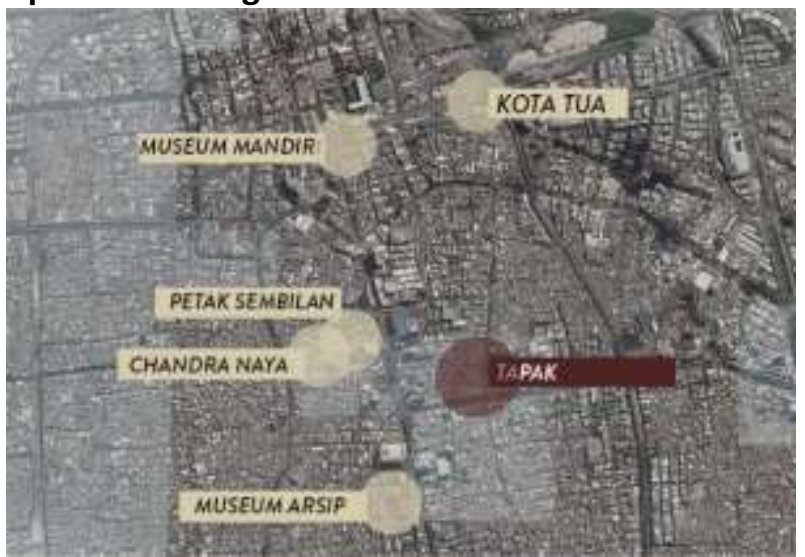

Gambar 3. Area Wisata Sekitar Tapak

Sumber: Dokumentasi Penulis, 2020

Tapak perancangan terletak di Jl. Mangga Besar V, Taman Sari, Jakarta Barat. Pada gambar 2, terlihat bahwa wilayah taman sari dikelilingi oleh area wisata kuno, seperti Pecinan Tua di Glodok, Chandra Naya, Kota Tua, dan lainnya. Hal ini dapat memberikan Taman Budaya peluang untuk menjadi salah satu pelengkap dari wilayah wisata bersejarah tersebut.

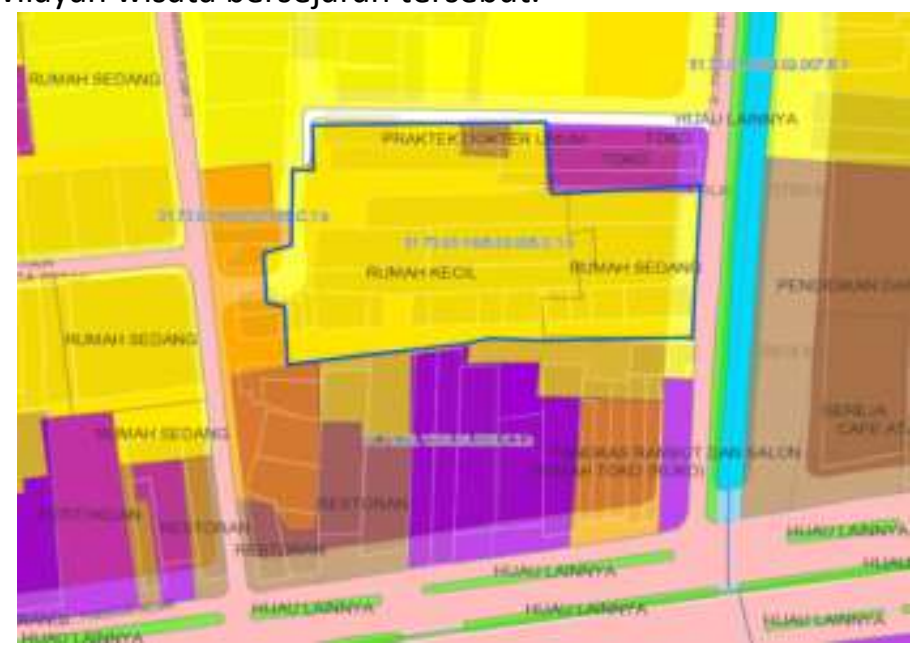

Gambar 4. Zonasi Tapak Perancangan

Sumber: Jakarta Satu (2019)

Tapak perancangan dikelilingi oleh zonasi campuran, yang sebagian besar memiliki fungsi first place dan second place (Peta Zonasi Kawasan Mangga Besar, 2019). Hal ini membuat Taman Budaya masuk dalam kategori third place. Selain itu, tapak perancangan berada di dekat Halte Busway Olimo dan Stasiun Kereta Mangga Besar. Tapak dapat dicapai dengan jalan kaki, motor, atau mobil. Jalanan di sekitar tapak memiliki lebar $6 \mathrm{~m}$, disertai oleh tenda warung di sekitar jalan. Warung tersebut menyempitkan jalan dan cenderung mengakibatkan kemacetan. 


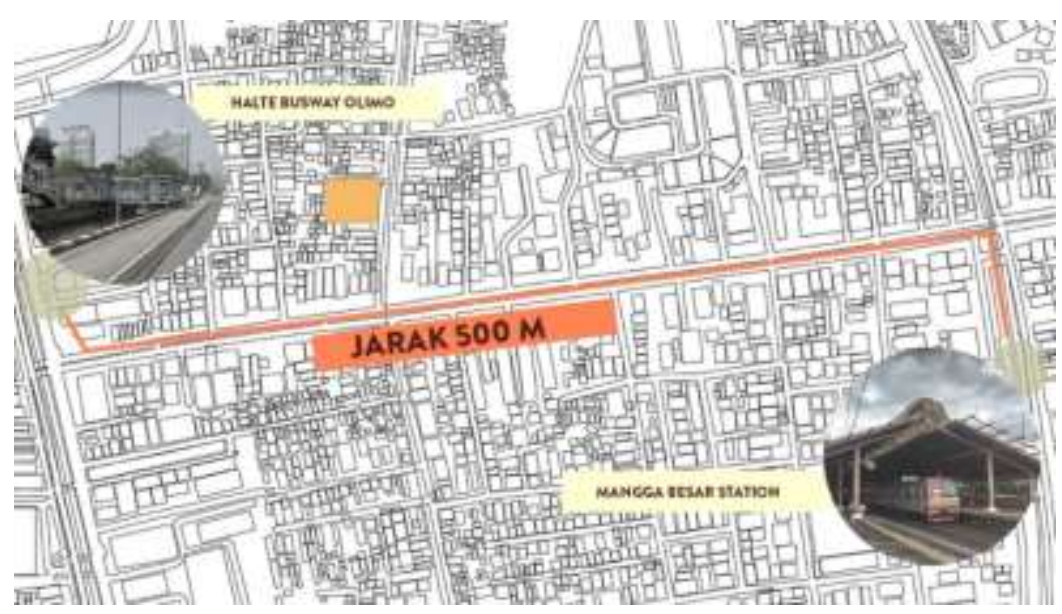

Gambar 5. Aksesibilitas Tapak

Sumber: Dokumentasi Penulis 2020

\section{Penetapan Program Bangunan}

Taman Budaya memiliki fungsi fleksibel sebagai tempat wisata kebudayaan, tempat bersantai, maupun tempat untuk berdiskusi secara informal bagi para pelajar dan pekerja kantoran di sekitar tapak. Fungsi tersebut dikaji sesuai dengan konteks kawasan, yang dimana sebagian besar merupakan zona campuran dan usaha, serta terdapat pula sekolah-sekolah. Para pekerja dan pelajar membutuhkan tempat yang strategis untuk beristirahat dan bersantai. Berikut merupakan fungsi utama dari Taman Budaya:

a. Taman Terbuka: Sebagai sarana anak-anak bermain, dan orang dewasa berdiskusi secara santai. Komunikasi merupakan kegiatan utama.

b. Workshop Kebudayaan: Ruang workshop diisi oleh kegiatan seni tari.

c. Kuliner: Menyediakan tempat untuk warung yang terletak di jalan depan tapak. Terdapat pula café yang dapat menjadi sarana pelajar dan karyawan kantor untuk berdiskusi secara informal.

d. Hall Multifungsi: Hall multifungsi dapat dimanfaatkan sebagai sarana kegiatan keadatan, pameran, live music, dan lainnya.

e. Galeri: Sarana bagi seniman lokal untuk memamerkan karya dan bersifat sementara.

\section{Penggunaan Metode Energi Positif}

Energi positif disini dapat di atasi dengan permainan cahaya. Seorang pengamat arsitektur, Margarete (2018) mengutip beberapa teori cahaya dalam arsitektur, yaitu:

a. Jendela yang besar berperan besar dalam mengembangkan kinerja kognitif pelajar, orang dewasa yang sehat, serta pasien di tahap awal dementia. Dengan itu, bangunan akan mengoptimalkan penggunaan cahaya alami dengan baik. Bangunan banyak menggunakan jendela, serta terdapat bukaan-bukaan. Pada malam hari, bangunan akan banyak memainkan cahaya buatan, sehingga tetap terkesan terang (Robinson, Yan, Soler, \& Núñez, 2017)

b. Cahaya matahari pagi mendukung kesehatan dan aktivitas manusia (Leslie, 2003).

Dengan teori tersebut, untuk menambah energi positif pada bangunan.

\section{Penggunaan Metode Simbiosis}

Tema budaya tionghoa diperlihatkan pada bentuk eksterior bangunan, sedangkan tema budaya betawi diperlihatkan pada material bangunan. Rangka atap menggunakan rangka kayu, dengan bentuk atap khas budaya tionghoa. Dinding eksterior menggunakan pelapis batu hias, agar terlihat segi tradisionalnya. Bagian interior banyak menggunakan pelapis kayu seperti pada bangunan adat betawi. Warna pada bangunan menggunakan ciri khas dari kedua budaya, yaitu warna yang terang dan mencolok seperti merah, hijau, coklat. 


\section{Penggunaan Metode Form Follows Function}

Pada mulanya, program bangunan di tata sesuai dengan konsep luo shu, lalu bentuk massa bangunan dirancang sesuai dengan fungsi ruangan yang telah diletakkan sesuai dengan konsep luo shu.

\section{Penggunaan Metode Luo Shu}
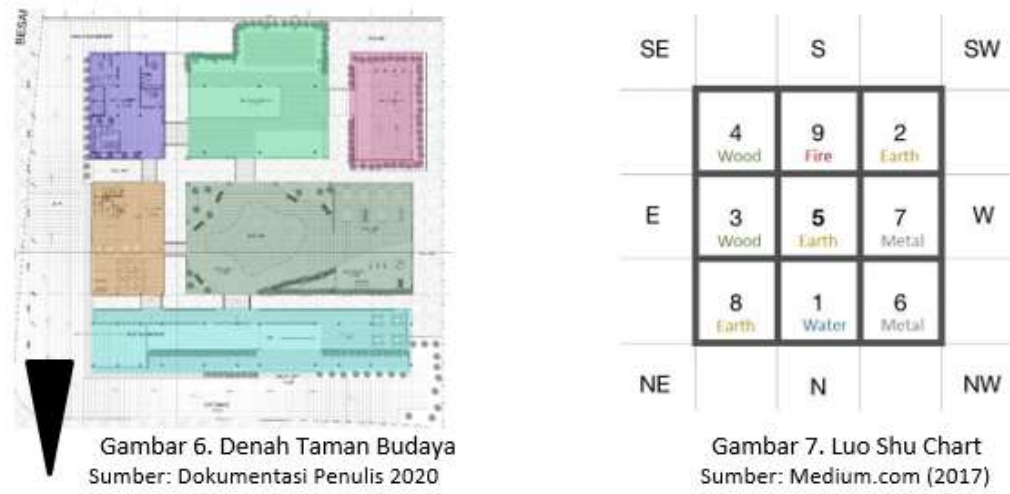

Gambar di atas menunjukkan perbandingan antara denah taman budaya dengan kotak luo shu. Bangunan menghadap ke arah utara, mengikuti arah arus sungai di samping tapak perancangan. Secara garis besar, bangunan bersifat massif dengan taman di tengah bangunan tersebut. Massa dibuat terpisah untuk mendapatkan pengudaraan alami melewati bangunan tersebut. Berikut merupakan penjelasan mengenai hubungan luo shu dan denah bangunan:

a. Warna biru muda melambangkan area pintu masuk yang terdapat di sisi utara. Bagian pintu masuk menghadap ke arah utara, dimana terdapat fase air yang bersifat menenangkan dan menyejukkan, agar area penyambut dapat menenangkan para pengunjung.

b. Warna jingga melambangkan area kuliner yang terdapat di sisi timur, warna ungu melambangkan area servis yang terletak pada sisi timur. Dari pintu masuk terdapat 2 koridor kecil yang menuju ke area food street dan courtyard. Area food street terdapat di bagian timur, dimana terdapat fase kayu yang melambangkan pertumbuhan, serta perluasan energi ke segala arah.

c. Warna hijau muda melambangkan area multi function hall dan galeri, Di belakang courtyard terdapat multi function hall yang terletak di fase api, dimana fase api dapat memuncakkan semangat pada acara-acara yang akan di gelar di multi function hall maupun di galeri tersebut

d. Warna merah muda melambangkan area meditation hall yang terletak pada sisi barat, . Di samping multi function hall terdapat area meditasi yang terletak di fase tanah. Area meditasi disini terletak di jauh dari area pintu masuk dan jalan raya, untuk menambahkan ketenangan.

e. Warna hijau tua melambangkan area courtyard dan taman. Courtyard berada di fase tanah, berfungsi sebagai pusat aktivitas. Play ground terletak di fase logam.

f. Terdapat area servis di fase kayu. Area servis terletak di dekat pintu keluar untuk memudahkan pengunjung keluar dalam keadaan darurat.

\section{Hasil Akhir Perancangan}
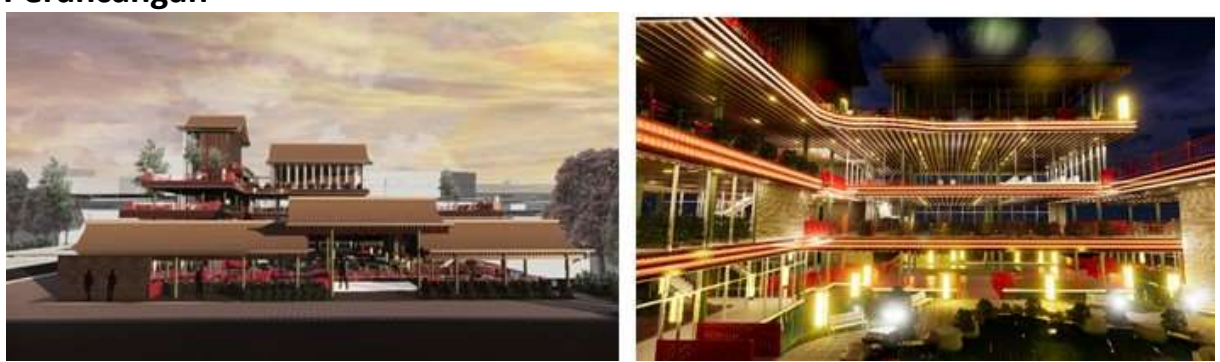

Gambar 8. Eksterior Bangunan Sore dan Malam Sumber: Dokumentasi Penulis 2020 
Taman Budaya Mangga Besar memiliki massa yang bersifat kubisme, serta memiliki 5 lantai bangunan. Hal ini dimaksudkan untuk menyesuaikan bangunan dengan konteks bangunan sekitar, sehingga tidak mengganggu skyline dan karakter dari kawasan. Pada bagian exterior, Taman Budaya Mangga Besar mengadopsi tema fasad arsitektur tionghoa. Warna pada fasad bangunan menggunakan warna-warna yang secara umum terdapat di rumah adat betawi dan tionghoa, yaitu merah, coklat dan hijau. Pada bagian exterior juga terdapat hiasan lampu LED untuk menambahkan penerangan bangunan saat malam hari, serta menambahkan kesan mengundang untuk para pengunjung. Bagian exterior menggunakan banyak material alami, seperti bebatuan untuk lanskap, lantai yang bermaterial batu alam, kayu untuk kisi-kisi dinding dan hiasan lampu di bagian tepi bangunan, serta lantai kayu. agian interior bangunan banyak menggunakan kaca, untuk menambah cahaya alami yang masuk. Material interior yang digunakan tidak jauh berbeda dengan material exterior bangunan.

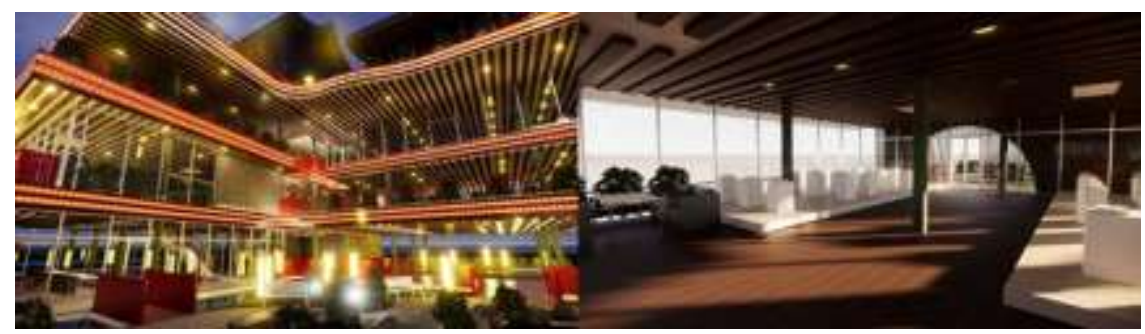

Gambar 9. Courtyard dan Cultural Gallery

Sumber: Dokumentasi Penulis 2020

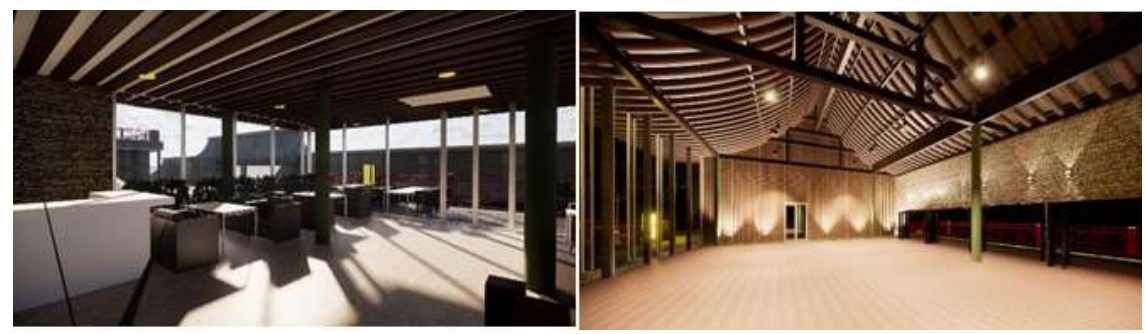

Gambar 10. Café, Multifunction Hall

Sumber: Dokumentasi Penulis 2020
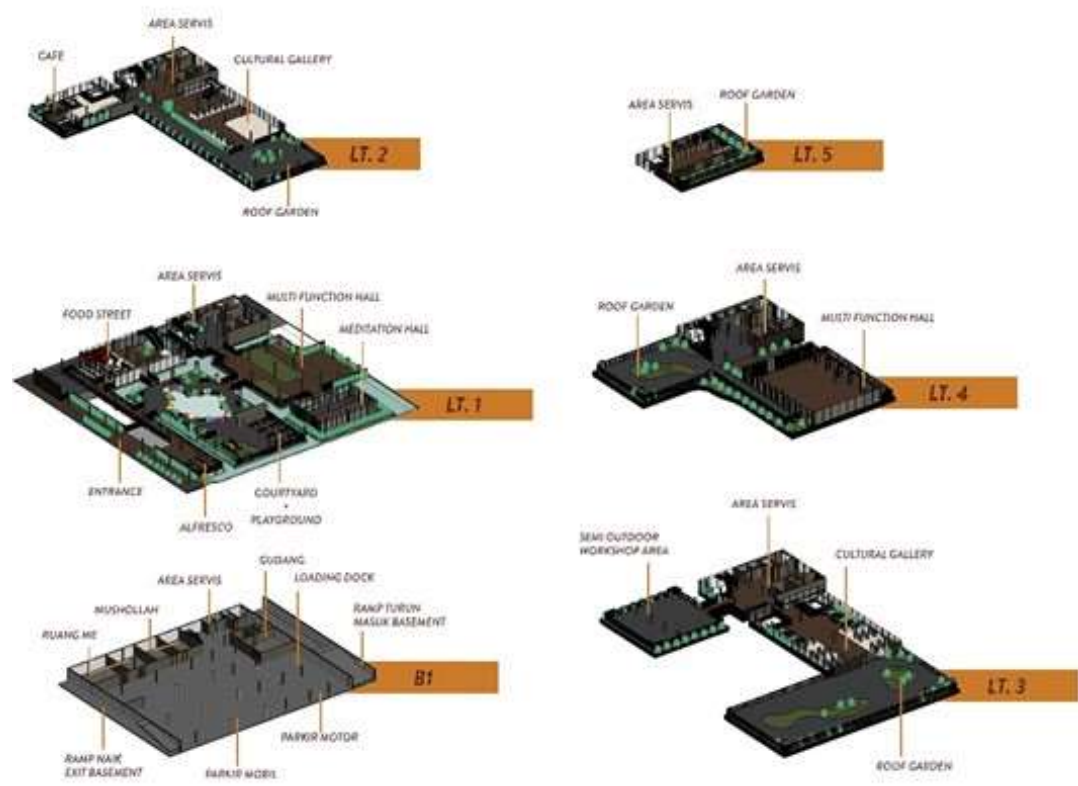

Gambar 11. Axonometri Denah Taman Budaya Sumber: Dokumentasi Penulis 2020 
Untuk menambahkan kesan tenang dan sejuk pada bangunan, pada lantai dasar terdapat kolam di antara massa yang tepisah. Hal ini dimaksudkan untuk menambah kesan floating, serta menambah kesan siheyuan yang tenang dan natural, tidak umum terdapat pada bangunan sekitar tapak. Terdapat pula beberapa roof garden pada bangunan. Roof Garden disini berfungsi untuk orang bersantai, berbincang-bincang. Roof garden lantai 2 dan 3 dapat dijadikan area pameran outdoor dikarenakan berhubungan langsung dengan cultural gallery. Pada roof garden lantai 4 dapat disewakan untuk acara yang sedang berlangsung di multi function hall lantai 4 , dan dapat bersifat lebih tertutup.

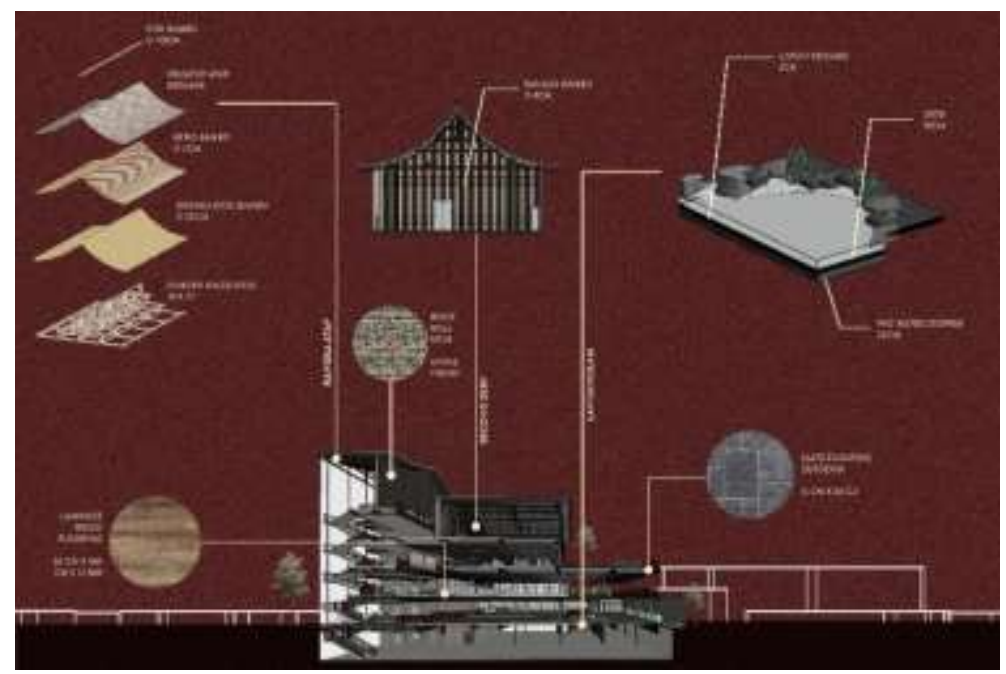

Gambar 12. Potongan Perspektif dan Material Bangunan Sumber: Dokumentasi Penulis 2020

Bagian interior pada multi function hall lantai 4 dan cultural gallery menggunakan kisi-kisi yang terbuat dari bambu dengan diameter $4 \mathrm{~cm}$. Lantai pada interior bangunan menggunakan lantai kayu. Pada bagian semi outdoor seperti workshop area pada lantai 3, menggunakan lantai bermaterial batu alam. Pada kolam yang tersebar di sekitar tapak, menggunakan water stopper berbahan PVC. Atap bangunan menggunakan gabungan antara kayu jati dan bambu. Penutup dari atap menggunakan bahan keramik.

\section{KESIMPULAN DAN SARAN Kesimpulan}

Indonesia memiliki banyak kasus mengenai intoleransi. Intoleransi dapat diatasi dengan pendidikan sejak dini mengenai budaya. Oleh karena itu, hasil akhir perancangan merupakan taman budaya bersifat edukatif yang bersifat santai dan informal, serta termasuk dalam kategori third place, yang memiliki gabungan antara tema budaya betawi dan budaya tionghoa. Adapun metode dan teknik yang digunakan dalam perancangan, antara lain:

a. Pemahaman Kawasan Jakarta Barat

b. Pemahaman Mengenai Tapak Perancangan

c. Penetapan Program Bangunan

d. Penggunaan Metode Energi Positif

e. Penggunaan Metode Simbiosis

f. Penggunaan Metode Form follows function

g. Penggunaan Metode Luo Shu

h. Hasil Akhir Perancangan

Teori perancangan yang digunakan pada proyek merupakan metode simbiosis oleh Kisho Kurokawa dan Metode form follows function oleh Louis Sullivan. Dua konsep berbeda yang akan digabungkan 
disini merupakan konsep budaya betawi dan budaya tionghoa. Konsep pemetakan menggunakan konsep luo shu dari arsitektur tionghoa. Material dan warna menggunakan material bangunan adat dari keduanya. Bentuk bangunan mengikuti fungsi yang diterapkan sesuai dengan konsep luo shu.

\section{Saran}

Saran yang dapat penulis sampaikan kepada para tenaga ahli di bidang arsitektur maupun mahasiswa arsitektur untuk kedepannya adalah, penulis harap para tenaga ahli dan mahasiswa arsitektur dapat memahami lebih lanjut mengenai budaya betawi dan tionghoa, dalam merancang bangunan yang memiliki tema dari kebudayaan tersebut. Selain itu penulis juga menyarankan untuk lebih lanjut mempelajari feng shui, dalam merancang bangunan yang memiliki konsep adat tionghoa dan fengshui.

\section{REFERENSI}

(2019). Diambil kembali dari 15 July 2019, google.com: https://www.google.com/earth/

Ahrendts, A. (2013). The Power of Human Energy. (A. Ahrendts, Pemain) TED Talk, Hollywood, California , Amerika Serikat .

Benyon, L. (2019). Harnessing the Power of Positive Energy with Architect Zhang Xi. Diambil kembali dari www.freundevonfreunden.com: Benyon, Luc. 2019. Harnessing the Power of Positive Energy with Architect Zhang Xi, diunduh 11 Februari 2020 (10.29 WIB), https://www.freundevonfreunden.com/interviews/harnessing-the-power-of-positive-energywith-architect-zhang-xi/.

Farid, M., 2018, Memahani Intoleransi dalam Ruang Publik. Diambil kembali 27 Desember, dari geotimes.co.id: https://geotimes.co.id/opini/memahami-intoleransi-dalam-ruang-publik/

Jakarta, B. P. (2019). Provinsi DKI Jakarta Dalam Angka 2019. DKI Jakarta: Badan Pusat Statistik Provinsi DKI Jakarta.

KBBI. (t.thn.). Intoleransi menurut KBBI. Diambil kembali dari kbbi.web.id: KBBI. Intoleransi, https://kbbi.web.id/intoleransi

Leslie, R. (2003). Building and Environment. Capturing the daylight dividend in buildings: why and how?, 381-385.

Nugraheny, D. E. (t.thn.). Ini Tiga Sebab Menguatnya Sikap Intoleransi di Indonesia Versi Polri . Diambil kembali dari nasional.kompas.com.

Oldenburgh, R. (1997). The Great Good Place. Dalam R. Oldenburgh, The Great Good Place. Massachusetts: Da Capo Press.

Peta Zonasi Kawasan Mangga Besar. (2019). Diambil kembali dari jakartasatu.jakarta.go.id.

Robinson, A. J., Yan, L., Soler, J. E., \& Núñez, A. A. (2017). Light modulates hippocampal function and spatial learning in a diurnal rodent species: A study using male nile grass rat (Arvicanthis niloticus).

Romadoni, A., 2017, 3 Langkah Pemerintah Menangkal Intoleransi di Indonesia . Diambil kembali 17 Januari 17, dari liputan6.com: ttps://www.liputan6.com/news/read/2828912/3-langkahpemerintah-menangkal-intoleransi-di-indonesia

Sotier, M., 2018, 2\# ARCHITECTURAL PSYCHOLOGY: The Influence of Architecture on our Psyche. Diambil kembali 11 Juni 11, dari medium.com: https://medium.com/archilyse/2-the-impact-ofarchitecture-on-our-psyche-cd48f4206016

Studio, F., 2017, What Is Luo Shu? Diambil kembal bulan April 2019 dari medium.com: https://medium.com/@floustudio/what-is-luo-shu-\%E8\%90\%BD\%E6\%9B\%B8-81971ec0c331 
Sudikno , A., Salura , P., \& Kustedja, S. (2012). Kosmologi Media Interpretasi Makna pada Arsitektur Tionghoa Tradisional, 202-203.

Sustainable Development Goals. (t.thn.). Diambil kembali dari sdg2030indonesia.org: https://www.sdg2030indonesia.org/

Swetz, F. (2008). Legacy of the Luoshu: the 4000 year search for the meaning of the magic square of order three. Massachusetts: A K Peters, Ltd.

Trisno, R., \& Lianto, F. (2019). Realization of Hybrid Concept and Symbiosis in Green Open Space (RTH) at Housing Complex RW (Neighborhood Councils) Pluit, Jakarta Utara, Indonesia.

Trisno, R., \& Lianto, F. (2019). Relationship Between Function-Form in The Expression of Architectural Creation. 
